\title{
OVERLOOKED AND UNDERSTUDIED? A Survey of Current Trends in Research on Adult English LANGUAGE LEARNERS
}

\author{
JULIE MATHEWS-AYDINLI \\ Bilkent University
}

\begin{abstract}
This article provides a synthesis and review of 41 recent research studies focusing on the population of adult English language learners (ELLs) studying in nonacademic contexts. It notes the unique qualities and importance of understanding the English-language needs of this population, provides a critical overview of the existing literature, and concludes that both more research and research from diverse methodological perspectives are necessary.
\end{abstract}

Keywords: literature review; adult English language learners; immigrants; refugees; ESL; ELL; research

\section{Adult English Language Learners (ELLs)}

The population of adult immigrants, refugees, migrant workers, and naturalized citizens studying nonacademic English as a second language in North America is large and growing. In the United States, nearly $45 \%$ of the adults enrolled nationwide in state-administered adult education programs attend English as a second language (ESL) or English literacy classes, bringing the official number of such students to approximately 1.2 million in 2003-2004 (U.S. Department of Education, Office of Vocational and Adult Education, 2006); and making this the fastest growing segment of learners in adult education programs (Yang, 2005). Combined with the large numbers of adults studying English in privately sponsored programs, volunteer literacy services, community-based programs, or workplace ESL classes, these adults represent a significant student body.

They also represent a group of learners with unique expectations and needs. They differ from other adult ESL learners, such as international students at

JULIE MATHEWS-AYDINLI, PhD, MA, is assistant professor and director of the MA TEFL Program at Bilkent University in Turkey (e-mail: julie@bilkent.edu.tr).

ADULT EDUCATION QUARTERLY, Vol. 58 No. 3, May 2008 198-213

DOI: $10.1177 / 0741713608314089$

() 2008 American Association for Adult and Continuing Education 
universities in North America, in many ways because of this very diversity. These adult learners are generally considered to range in age from 16 to 90 -plus, in educational background from no formal schooling to $\mathrm{PhD}$ holders, and in native language literacy levels from advanced to pre-literate. Their corresponding needs range equally widely, from basic literacy and/or survival English skills, to transitional classes to help them prepare for higher education in English. By contrast, ESL students in colleges and universities tend to fall into a more limited age range, can be counted on as having at least a high school-level education and a reasonably advanced level of literacy in their native language, and as college or university students, share an obvious common need for training in academic English skills.

There are indications in recent years that the needs of these adult ELLs are not being fully met. Despite the best efforts of adult ESL teachers-many of whom are volunteers-dropout rates among adult ESL students remain a problem, and achievement is at best inconsistent. Looking at the largest linguistic subgroup among adult ESL learners, the results of the 2003 National Assessment of Adult Literacy (NAAL) showed that in the 11 years since the previous national survey, the English prose and document literacy levels of Hispanic adults in the United States have fallen significantly ( $18 \%$ and $14 \%$, respectively), and their quantitative literacy scores have remained unchanged (Kutner, Greenberg, \& Baer, 2005). Another recent analysis shows that of foreign-born adult Hispanics, approximately $73 \%$ speak English "less than very well," and for Asian adults, $40.4 \%$ fall into this category (Fry \& Hakimzadeh, 2006).

At the same time, there is increasing political discussion and thus interest in the language skills and subsequent "employability" of these adult ELLs. From the President on down, the correlation between postsecondary education and trainingfor which adequate English skills are essential-and economic stability is frequently argued. The apparent inconsistency between such an agenda for adult higher education and the realities of achievement raises immediate and important questions about the nature of language learning and teaching with respect to this community of students. What, for example, are the unique characteristics of these particular adult ELLs' language learning processes? What external factors have the greatest impact on their language learning success or failure? What are the most effective curricula and pedagogical approaches for these students?

Unfortunately, possible answers to these and other questions are often anecdotal and unsubstantiated. Not only do adult ELLs studying nonacademic English remain an understudied population in the academic scholarship on second-language acquisition (SLA) and education, the research studies that do exist often lack a theoretical base and thus remain disconnected from each other, making it difficult to draw the conclusions necessary to answer questions like those above. No study to date has looked at the full scope of research on this particular population of learners to understand the exact extent of its neglect in the literature or to provide an accurate picture of what research does exist. Johnson's 2001 annotated bibliography of the 12 works on SLA in adults that were 
available at that time in the ERIC database focuses on actual SLA research-that is, studies investigating the linguistic processes of adults learning a second language. It is not restricted to studies on adults in nonacademic settings and does not include adult ELL works investigating things other than linguistic processes of learning-studies that she criticizes (not inaccurately) as generally "observational" and dealing with program issues. Although her focus is understandable, it leaves the field still lacking in any comprehensive picture of adult ELL research from which to try and draw conclusions.

This article provides a broad overview, therefore, of the recently published literature on adult ELLs in nonacademic settings to clarify the extent and nature of this research and to explore any emerging trends within this area of study. It focuses on works dating from 2000 onward, first because Johnson's bibliography provides the field with some picture of the literature prior to 2000; and second, for manageability, it is necessary to set certain limits on how much literature can be covered. With this information compiled from studies spanning the past 6 years, we may learn what answers are already out there to questions like those raised above and better understand what directions future research on this particular student population needs to take.

\section{Adult ESL Research}

The studies considered for this article were compiled by conducting a general search of the keywords "adult ESL" in two primary academic indexes: EBSCOhost (which includes Academic Search Premier, ERIC, and Educational Abstracts) and Linguistics and Language Behavior Abstracts, between them covering thousands of academic journals and dissertations worldwide. These simple keywords were chosen to generally restrict the results to studies in ESL situations in North America, the United Kingdom, or Australia (as opposed to English as a foreign language contexts, in which the students' needs and profiles are distinctively different from adult ESL learners learning English as immigrants or refugees); but was otherwise broad enough to allow for all studies with adults to be initially identified. The resulting list was then pared to primary research studies dating from 2000 to the present and to those studies that dealt with adult English language learners outside of higher education contexts. In other words, studies focusing on international students in North American universities or on adult students taking ESL classes to complement their disciplinary coursework in colleges and universities were removed, leaving those studies focused on adult learners in government sponsored or community-based English language programs. " Using the keywords "adult ESL" also meant that studies on adult basic-education learners were not covered. Although this literature has occasional insights for adult ELLs, such as when it deals with practical concerns like how to juggle work, family, and an evening adult education course, its primary focus is on native English speakers in adult education or literacy programs-a population 
with completely different linguistic, cultural, and often educational backgrounds from those of adult ESL learners and thus of marginal relevance when answering questions about these adults' second-language learning processes or experiences.

The result was a total of 41 works: 23 published articles and 18 unpublished dissertations. Based on methodology and focus, these works were then roughly divided into three broad categories: ethnographic studies, teacher-related studies, and second-language acquisition studies. The details of each category and corresponding research are discussed below; however, the overall distribution of the studies shows a majority of ethnographic works (23), followed by teacher-related studies (12), and finally, SLA studies (6; see Table 1).

As with all research, the studies described below vary not just in terms of methodological approach but also in terms of quality within those approaches. Among the qualitative studies in particular, there are numerous inconsistencies in their conduct. Some researchers cited fail to describe their methodological approach adequately to allow for proper assessment, let alone replication, of their studies. Others fail to locate their work within a theoretical framework that would permit the reader to easily understand the author's perspective and would permit the work and its findings to contribute to an identifiable segment of the literature. Some studies noted here employ methodologies of questionable reliability-from spending a limited time with the community under investigation and failing to triangulate data collection methods, to providing insufficient and unconvincing evidence to make the researcher's interpretations and conclusions clear and credible. Having said this, the goal in the following sections is not to isolate particular studies and point out flaws in their design or conduct but, rather, to attempt to understand the broader state of the literature-a task made that much more challenging because of the shortcomings noted above.

\section{Ethnographic Studies}

Clearly, the largest group, ethnographic studies, also comprises the broadest category in terms of definition. Most of these studies revolve in one way or another around questions of identity, power, and socialization, sometimes with respect to specific ethnic communities, sometimes in terms of adult ELLs in general. Some focus on particular aspects of language (i.e., pronunciation), socialization (i.e., prejudice), or language learning (i.e., motivation). Others simply describe adult ESL programs and offer recommendations accordingly.

Looking first at studies focused on particular ethnic communities, Bernat (2004) surveyed Vietnamese ELLs in Australia for possible correlations between their beliefs about language learning and their motivation. Interestingly, despite their beliefs that as adults, they were at a great disadvantage in language learning, and despite their widespread lack of confidence in their own language-learning abilities, all had high motivation. The findings indicated that this stemmed largely from external motivating factors, primarily the need to find work. 
TABLE 1

Distribution of Study Types

\begin{tabular}{|c|c|c|c|}
\hline & Ethnographic & Teacher-Based & $S L A$ \\
\hline Published articles & $\begin{array}{l}\text { Bernat (2004) } \\
\text { Buttaro (2001, 2004) } \\
\text { Derwing (2003) } \\
\text { Gault (2003) } \\
\text { Gordon (2004) } \\
\text { Hubenthal (2004) } \\
\text { King (2000) } \\
\text { Menard-Warwick (2005b) } \\
\text { Schomburg (2004) } \\
\text { Skilton-Sylvester (2002) } \\
\text { Warhol (2004) }\end{array}$ & $\begin{array}{l}\text { E. M. Ellis }(2002,2004) \\
\text { Gunn (2003) } \\
\text { Hird et al. (2000) } \\
\text { Kim (2005) } \\
\text { Morgan (2004) } \\
\text { Wu \& Carter }(2000)\end{array}$ & $\begin{array}{l}\text { Brindley \& Slatyer (2002) } \\
\text { Izumi \& Izumi (2004) } \\
\text { Panova \& Lyster (2002) } \\
\text { Reder et al. (2003) }\end{array}$ \\
\hline Dissertations & $\begin{array}{l}\text { Carpenter (2005) } \\
\text { Hwang (2003) } \\
\text { Hyman (2002) } \\
\text { Jeon (2005) } \\
\text { Kristjansson (2004) } \\
\text { LaBelle (2005) } \\
\text { McVay (2004) } \\
\text { Menard-Warwick (2005a) } \\
\text { Palacios (2002) } \\
\text { Warriner (2003) } \\
\text { Yeh (2005) }\end{array}$ & $\begin{array}{l}\text { Bonissone (2003) } \\
\text { Gault (2004) } \\
\text { Gilbertson (2000) } \\
\text { Maum (2003) } \\
\text { Shono (2005) }\end{array}$ & $\begin{array}{l}\text { Adams (2005) } \\
\text { Lee }(2000)\end{array}$ \\
\hline Total & 23 & 12 & 6 \\
\hline
\end{tabular}

NOTE: SLA = second-language acquisition.

Several studies (Buttaro, 2002, 2004; Carpenter, 2005; Gault, 2003; MenardWarwick, 2005a, 2005b; McVay, 2004) looked at the experiences of Hispanic/ Latino/Mexican ELLs in the United States. Among these, a common element noted was the critical role of the family in promoting learner success. Other common points raised in these studies can likely be generalized to a broader adult ELL population, including the need to support ELLs by providing child care facilities, academic and work counseling, and help with transportation. For the classroom, recommendations were made to balance newer pedagogical approaches with more traditional teaching methods (that the students may expect and value), to set goals together, to address the students' realities-not our assumptions of what they might be, to first address the students' speaking and listening needs before reading and writing, and, if possible, to consider a combined classroom/ individual tutorial approach to teaching.

Warhol (2004) and Hubenthal (2004) both looked at elderly English learners, the first at female Liberian refugees, the second at Russian ELLs. Outside of the shared age factor, the groups differed quite substantially in educational backgrounds and motivations, and these differences were reflected in the findings of 
the two studies. The findings of Warhol's action research emphasized the mismatch between the women's own ideas regarding "success" in the governmentfunded program in which they were enrolled and the government's ideas. Although the government uses test scores to measure success, the women place more value on their active participation in the program and on their ability to complete assigned tasks. Hubenthal's Russian participants, unlike many younger, more extrinsically motivated adult ELLs, expressed being motivated to learn English to feel like competent, articulate, independent adults-a finding arguably reflecting their past education and professional identities. The participants also noted barriers to their learning that no doubt may be shared among older learners of any ethnic background. These included health problems and shame about poor memory ability and perceived language learning difficulties.

Two studies looked at Korean learners (Hwang, 2003; Jeon, 2005). The first looked at how the Korean community's efforts to promote biliteracy have contributed to the maintenance of the Korean language among Korean communities in the United States, and the second examined a case study of a Korean mother and her three children, showing how language learning is more than just language learning but, rather, constitutes a social process of reconstructing a new self in the target language culture.

Two other studies focusing on issues of identity with reference to specific ethnic populations are Gordon (2004) and Skilton-Sylvester (2002). SkiltonSylvester's case studies of four Cambodian women show how their motivation (investment) for learning English is directly tied in with the ways in which their various identities are recognized in the classroom. The author applauds efforts to incorporate students' cultural and social identities into program and curriculum design but cautions against simply creating new standards-for example, all Cambodian women can be expected to act and feel in a certain way, and therefore, we must teach them all in a particular manner appropriate to those expectations. Rather, she encourages curricula that can embrace the influences of multidimensional identities. Gordon's comparative study of male and female Lao students and their language socialization reveals an interesting element to the "multidimensionality" of gender identity. He found that as the Lao women socialized into the target language, they experienced a broadening of their identities, whereas the Lao men experienced a narrowing of theirs.

This brings us to the various studies on student identity and socialization among mixed groups of adult learners. Several studies looked at adult ELLs to explore how broader concepts of students' cultural, ethnic, and gender identities impacted their language learning experiences. Warriner (2003) showed how students position themselves and are positioned in educational and local contexts according to their choices with regard to language learning, and Kristjannson (2004) emphasized the importance of programs creating a caring community for the learners to be a part of. King's (2000) study on transformational learning provided clues to the particular classroom activities that students felt contributed 
most to their personal development. They emphasized the value of activities like discussions, writing about their personal concerns, group projects, and journal writing; and of topics like the English language, the host culture, and intercultural awareness. Palacios's (2002) case study of a literacy program looked at how students' and teachers' perspectives about literacy (e.g., viewing literacy as discrete skill development, as functional/survival skills, or as a personal/social empowerment tool) promotes the use of particular literacy events. Thus, for example, discrete skill perspectives are likely to lead to activities such as teaching alphabet lessons, whereas a functional perspective may lead to exercises like resume writing.

In two final sets of studies, Derwing (2003) and Hyman (2002) both looked at issues of foreign accent among adult ELLs. Hyman's quasi-experimental study contrasted native-English speaker responses to ELL students' speech before and after training and found a strong connection between judgments of accent and "occupational fit." In other words, those with strong foreign accents were deemed less suited to be hired for certain jobs. Focused pronunciation training was found to be helpful in improving the students' accents. Derwing's large-scale survey of adult immigrants in Canada found that although few felt that they had been openly discriminated against because of their accents, most admitted feeling that they would be respected more if they sounded more native-like. She also concludes with recommendations for teaching pronunciation-guided by intelligibility-and for exploring issues of accent and bias with classes of adult ELLs. Also dealing with issues of prejudice, though not as related specifically to accent, LaBelle (2005) and Yeh (2005) both found that their adult ELLs had experienced some prejudicial treatment in their relations with native English speakers-though not extensive. Both groups displayed various strategies for coping with prejudice stemming from, for example, the "English-only" perspective within the United States. These "counter-discourses" included using their native languages, ignoring the prejudicial attitudes, remaining silent, deflecting, and bypassing the offending behavior or speech.

Although one is first struck by the diversity of these studies, it is possible to pick out certain common threads running through them. Notable in particular among studies about adult immigrant ESL learners is an emphasis on practical issues, such as the importance of providing these students with physical, financial, and consulting help to improve their chances of success in learning English. On such practical or concrete matters, it would be useful to have some comparative studies between programs - both within the United States and with those in other countries-to clearly identify the most critical of these practical issues on language learning success as well as studies to compare the relative effect on language learning of these types of factors and more traditional SLA factors, such as classroom practices or learner differences.

Another point that emerges from these studies, and is no doubt a contributing factor to their overall disparate nature, is the need to recognize the diversity 
within the adult ESL population. This diversity can be seen by simply looking at the populations involved in these studies, which differ ethnically, in age, and in educational and professional backgrounds as well as in reported needs and preferences for learning English. This diversity makes it all that much more important that researchers focusing on adult English language learners identify and develop broad research themes along which to build up common knowledge within the field, rather than a kind of ad hoc approach, in which little or no attempt is made to connect studies with each other, and resulting in a collection of separate studies that seems to fall short of what we can define as a cohesive body of literature.

A final observation can be made about those studies touching on issues of identity and socialization and the broad questions that they raise about the expectations held for-and by-adult ESL learners. Presumably, teachers, program administrators, and government officials all want to see these students learning the English language adequately to permit them to live a comfortable and full life in a majority English-speaking environment. But how much English does that require? Should the goal of adult ESL classes be that the students learn to cope with the basic necessities of life or that they be progressing toward full integration into the native English speaking community? Basic questions like these are critical, because their answers ultimately determine the expectations held for these students and subsequently affect the curricula designed for them.

Such questions may also prove useful by providing a starting point for understanding the scattering of studies on adult ELLs' identity and socialization. When , considering the students' own expectations, studies like these remind us that these । adult learners are themselves often caught in a complex dilemma. They may want , to learn enough English to cope with practical needs, and to feel like the whole, respected, mature people that they are in their native language cultures and environments, but not to an extent that might risk a loss of those native cultures and languages. How do all these various perspectives (of teachers, students, administrators) on adult ELLs' identities within native English speaking societies and subsequent language learning expectations connect, conflict, or merge? And what is the result of such conflict or merging on the effectiveness of instruction and learning in adult ESL classes? Such questions remain as yet unanswered.

\section{Teacher-Related Studies}

This category consists of those studies focused on teachers in adult ESL programs - either as the subject of the studies themselves or in the case of action research studies, on particular teaching practices and the individual teacher's experiences and impressions. In the latter category, there is the example of Kim (2005), which describes the author's use of dialogue journals in a culturally diverse adult ESL classroom and shows how the use of those journals positively served to build a sense of community among the learners and as a source of valuable 
information for the teacher-helping her in the planning of lessons relevant to the students' linguistic and cultural needs. Also an action research study but examining the relationship between teachers' attitudes and student success is Gunn (2003). In this study from Australia, the author describes her experience with a class of low- and pre-literate adult ESL learners and how the explicit effort to avoid adopting a "deficit" view of the learners by seeing the class as an "opportunity" for literacy led to positive changes in her own attitudes and approaches-both in the school's relationship with the learners' communities, and in the curriculum. Bonissone (2003) reached similar results in her study, which was a collaborative study between the researcher and one literacy teacher. Again, efforts taken by the teacher to explore and reflect on how new approaches in the classroom led to progressive changes in the teacher's own beliefs and practices, interactions between her and the students, the overall learning environment, and types of literacy that her students used and produced.

Of the studies focusing on teachers in general, there was one relatively largescale study comparing practices of teachers of children and teachers of adults (Hird, Thwaite, Breen, Milton, \& Oliver, 2000). Hird et al. (2000) found some broad similarities between the teachers' practices, such as efforts to create a positive affective environment in the classroom, but also several differences. For example, the teachers of adult ELLs tended to use more drilling/repetition/ rehearsal exercises, paid greater attention to differences in students' proficiency levels and learning styles, and generally were more focused on outcomes and assessment than the teachers of children. The reason for the last of these was attributed to the Australian system of providing a limit of 510 hours of English lessons to adult immigrants, during which time they are expected to acquire adequate skills to pass the Certificate of Spoken and Written English.

E. M. Ellis (2002, 2004) and Maum (2003) explored teachers' beliefs and practices from the perspective of differences between native English-speaking and nonnative English-speaking adult ESL teachers. Maum conducted a largescale survey of native English-speaking teachers (NESTs) and nonnative Englishspeaking teachers (NNESTs) of adult ELLs. Both in statistical analyses and in subsequent interview data, significant differences between the two groups were observed. For example, NNESTs were more likely to see an important role for the teacher's own sociocultural and linguistic background in the classroom and in the inclusion of cross-cultural issues in ESL instruction. Ellis's studies have also shown differences between the teaching practices of monolingual versus multilingual (both NNESTs and NESTs with advanced proficiency in another language) adult ESL teachers. The author makes the argument that the teachers' own language learning experiences are a valuable resource for the adult ESL teacher and should be viewed as a positive-arguably, even required-attribute of ESL teachers.

Another qualitative study of ESL teacher experience is Morgan (2004), in which the bulk of the article is an in-depth analysis of the literature on teacher 
identity, followed by a narrative of the author's own experiences teaching in an adult ESL program in Canada. He explores the processes of how he and his students negotiated their various roles in the classroom, and in doing so all came to understand themselves better-challenging their own assumptions about culture, gender, and family roles.

Gault's 2004 study actually involves adult ESL students, but the focus of the inquiry was on their beliefs about "good teaching" in ESL and thus is of direct relevance to teachers-the argument being that if teachers' teaching practices fail to match students' assumptions, the resulting learning environment will be limited. In fact, Gault found that such mismatches do occur, primarily in the case of teachers adhering to solely communicative-based approaches and being reluctant to practice error correction of form, although the students tended to be familiar (and therefore expecting) of more traditional, even grammar-based approaches. Although Gault does not recommend giving up, therefore, on communicative approaches, he does suggest making clear the rationale for using them (preferably in the students' native languages) and balancing them with approaches and exercises that match the students' expectations. Shono (2005) also compared student and teacher beliefs in her effort to identify the characteristics of a "good teacher." Her results reveal such recommended personal attributes as being a respectful professional, a cultural mediator, caring and patient but also a student belief in the importance of the teacher being a native English speaker-an interesting point when we consider the findings of Maum and Ellis and their emphasis on the value of multilingual ESL/NNES teachers.

A final study on teacher practices is Wu and Carter (2000), which looked specifically at the work of volunteer teachers in a "successful" adult ESL program. Recommendations from the survey study include the following: (a) Encourage professionalism among volunteer staff, (b) appoint a director who can supervise the volunteers, (c) create a friendly atmosphere, and (d) allow for flexible schedules. These recommendations are well-taken when we consider the findings of Gilbertson (2000), whose general descriptive study of an adult ESL program concluded that without appropriate and adequate training, volunteer teachers could actually do more harm than good.

The teacher-related studies, unsurprisingly, evolve in one way or another around instructional practices and, directly or indirectly, around identifying important aspects of teaching adult ELLs effectively. Although the studies approach this task from very different angles and reach many different conclusions, it is possible to pick out one common thread that runs throughout them all-namely, a particular sensitivity toward the students' cultural backgrounds. For example, the studies emphasize the importance of building up good relations between the school and the students' local ethnic communities, the benefits of having teachers who can relate to the students' cultural backgrounds, and the role of ESL teachers as caring, patient cultural mediators. 
One could argue that culture is inseparable from language and, therefore, from all second-language teaching, but it seems that this consciousness of a need for cultural awareness and sensitivity is particularly strong within the literature on adult ELL instruction-more so, for example, than in studies on adults in EFL or academic ESL settings. Although culture and cultural understanding is emphasized in these studies as something for teachers and program administrators to pay attention to, it seems that the adult ELL population presents a still-undertapped resource for research on culture and second-language learning. Unlike young learners, whose cultural identities are perhaps less strongly entrenched (and are thus less immediate sources of conflict when learning a second language), or EFL learners who may never even meet with people from the target language culture, adult ELLs must negotiate culture and language issues on a daily basis. Clearly this subgroup of learners has much to offer the literature on this theme.

\section{Second-Language Acquisition Studies}

This final category is generally meant to encompass those studies in which adult ESL students were the participants but not necessarily the focus of the research: in other words, conceptual studies on various aspects or themes in SLA research, in which the students used in the conducting of the study happen to be adult ESL learners. The SLA concepts examined in these studies were learner-learner interactions (Adams, 2005), task difficulty in listening assessment (Brindley \& Slatyer, 2002), oral output (Izumi \& Izumi, 2004), the effect on oral proficiency of multimedia as an instructional tool (Lee, 2000), and corrective feedback and uptake patterns (Panova \& Lyster, 2002). The final work listed here doesn't clearly fit into any of the categories. Reder, Harris, and Setzler (2003) is not a research study but rather a report on the setting up of a database on the population of adult English-language learners in the United States. It describes an initiative of video- and audiotaping 5,000 classroom hours of low-level adult ESL learners in a community college. The tapes are being transcribed and coded for easy searching of linguistic and pedagogical factors both for longitudinal data and for detailed interlanguage data. I have included it in the SLA category because of the tremendous potential that this database project holds for enabling future research-both SLA studies in general and on adult ELLs in particular.

Of the conceptual study findings, some of the more interesting for adult ESL teachers include Adam's (2005) finding in a quasi-experimental study that interactions between learners, like interactions between ELLs and native English speakers, facilitates the learners' second-language acquisition-thus providing evidence to the value of classroom communicative teaching methods that promote learner-learner interactions. Izumi and Izumi's (2004) experimental study about using oral output tasks to promote grammar acquisition actually found that the control group receiving only oral input outperformed the treatment group. However, the researchers conclude that this may have been because the output 
tasks used were not appropriate. They recommend that to stimulate the kind of cognitive activity necessary for learning, different tasks are necessary: for example, having students first produce oral output in a task and then receive oral input on it (rather than the other way around), thereby eliminating the possibility of students simply memorizing and repeating certain forms. They also recommend using dictogloss activities with students, in which students listen to a text, take notes, and then work with a partner to reconstruct the text.

In terms of teacher practice, Panova and Lyster (2002) looked at patterns of corrective feedback given by teachers and how students responded to this feedback. They observed that teachers in the adult ESL class in question relied primarily on recasts and translation when providing feedback on student oral errors. Neither of these feedback types was found to be effective in promoting learner uptake and repair of errors. Although the authors do not recommend abandoning the use of these types of feedback, noting, for example, that recasts are useful for scaffolding purposes and in the case of errors that are beyond the students' current level, they do suggest incorporating feedback methods that encourage students' own retrieval and production processes. For example, teacher repetition of the error, elicitation of self-repair from the student, and request for clarification are more likely to result in student uptake and repair.

The two final studies in this category were Lee (2000), whose quasi-experimental study on the use of interactive multimedia instruction was found effective in developing the communicative competence of adult ESL learners, and Brindley and Slatyer's (2002) exploratory study on the validity and reliability of listening assessment tasks used in the Australian adult ELL testing. Their findings shed doubt on the fairness of using tests to measure listening competency, as they show the extreme complexity of determining what makes an assessment task "difficult," and thus able to be compared and scored in relation to other tasks. They emphasize the need for additional research on the interaction between texts, tasks, and individual learner variables.

Two things immediately stand out about this group of studies. First, their number is strikingly small. Compared with the studies in the first two categories, which can be largely classified as qualitative in methodological approach and data collection techniques, there are only a handful of quasi-experimental investigations. More important, however, is what these studies have to say about secondlanguage acquisition among the adult ELL population in particular-which is not a great deal. Three of the five research studies use adult ELLs to add evidence to ongoing debates in SLA research and do so convincingly for discussions on the benefits of student-student interaction and on the predominance of recasts as oral corrective feedback; and less convincingly for the idea that oral output promotes grammar acquisition. The other two studies again "use" adult ELLs to show the effectiveness of a particular teaching tool on improving communicative competence and to explore the reliability and validity of listening comprehension tests. 
None of these studies is explicitly concerned with the SLA processes of this particular subsection of adult second-language learners, which is why there are no studies, for example, contrasting the differences between adult ELLs and another population, as based on interaction patterns or corrective feedback and uptake. This is to be expected, because interesting differences, in terms of secondlanguage acquisition, are seen between learners of different ages, or linguistic backgrounds, or perhaps learning styles or preferences. For the researcher looking at interaction patterns or oral recasts, whether one's participants are adult ESL learners studying in a university ESL classroom or a church basement is irrelevant. If we ask what is unique about the adult ELL population (in nonacademic settings) that would be of interest to researchers of second language learning and teaching, we are brought back to questions of these students' life experiences, and to issues of culture and identity, and the respective roles of these factors in the second-language learning process. It is unsurprising, therefore, that these are the issues dominating this small but growing area of research.

\section{Conclusion}

The numbers alone in this survey point clearly to the main problem surrounding research on adult ELLs: There is still not enough research being conducted on this specific population of second-language learners. Despite the number of published studies coming out of Australia, Canada, England, and the United States, the vast majority of research with adults, whether in ESL or EFL contexts, still tends to surround those learners in higher education contexts-perhaps an unsurprising situation because that is the context in which the researchers themselves tend to work. Unfortunately, the contextual and individual-level differences between most ESL/EFL students in higher education and adult ESL students in nonacademic contexts are so great, that research with one group has often little significance or relevance for the other. This argument is equally true for research on adult basic education or adult literacy-a category into which adult ELLs are often erroneously placed but which actually focuses on the very different needs of native English-speaking adults. There remain, therefore, many channels of inquiry that have yet to be explored with adult ESL learners. On a positive note, the number of dissertations being written on the adult ELL population has been growing in recent years, suggesting that the numbers of future published works will increase as well.

The second "problem" with the research on adult ELLs concerns the nature of the research that actually is being conducted. Whether or not one considers this a problem depends on one's perspective on research and on the methodological and epistemological approaches we espouse. Currently, most studies being conducted are of an ethnographic nature, are case studies, or involve qualitative data collection methods. Although, admittedly, several of these studies would have benefited greatly from the advice of standards setting articles in qualitative research (e.g., 
Chapelle \& Duff, 2003), it is nonetheless unfortunate that such studies may not be given the attention that they deserve in the current political environment, which prioritizes quantitative, experimental data collection and analysis. If we agree that research on adult ELLs will have the greatest ultimate impact when it can be used to influence education policy or funding, then arguably efforts must be made at this time to also produce research that policy makers are more likely to consider. This might include, for example, studies showing that systematic or concentrated attention on factors that current research suggests are important to successful language learning in adult ELLs can actually-and measurably-be shown to raise communicative competence.

This is not an unreasonable request. Most researchers can agree that different research approaches and methodologies all have their place and time, and the optimal route to constructing a comprehensive body of scholarly knowledge is for such diverse approaches to build on and complement one another. So, although descriptive studies play an important role in identifying factors and issues of importance for a certain group of learners, qualitative studies can provide deeper understandings about these factors and the relations between them; and quantitative studies can attempt to test for significance in these relationships. It is heartening to see the emergence of projects such as the adult ESL learner corpus at Portland State University, which will no doubt provide extremely valuable and measurable data to be explored further in different studies. Ultimately, though, if the diverse research studies being conducted on adult ELLs are to mature into a settled body of literature, one that can convincingly contribute to our knowledge of how this population learns and should therefore be taught, they will need to adopt consistent standards of quality, commonly recognized themes of inquiry, and a more evenly balanced diversity of methodological approach.

\section{NoTe}

1. This search also did not include works on the specifics of workplace literacy but concentrated on research done in "regular" adult ESL programs, both private and government-sponsored. A good starting point for looking at fairly recent research studies on workplace literacy is the 2000 special issue of The Canadian Modern Language Review (Vol. 57, No. 1; see studies by Bell, Katz, and Duanduan).

\section{REFERENCES}

Adams, R. J. (2005). Learner-learner interactions: Implications for second language acquisition. Dissertation Abstracts International, 65(9), 3355A.

Bernat, E. (2004). Investigating Vietnamese ESL learners' beliefs about language learning. English Australia Journal, $21(2), 40-54$.

Bonissone, P.R. (2003). Teacher change and professional conversations: A case study of an ESL instructor's changing beliefs and practices regarding literacy learning and instruction. Dissertation Abstracts International, 63(11), 3834A. 
Brindley, G., \& Slatyer, H. (2002). Exploring task difficulty in ESL listening assessment. Language Testing, 19(4), 369-394.

Buttaro, L. (2002). Understanding adult ESL learners: Multiple dimensions of learning and adjustments among Hispanic women. Adult Basic Education, 1I(1), 40-61.

Buttaro, L. (2004). Second language acquisition, culture shock, and language stress of adult female Latina students in New York. Journal of Hispanic Higher Education, 3(1), 21-49.

Carpenter, S. F. R (2005). "Ingles es loco": Teaching English to Latinos who don't speak English and who have varying levels of literacy in Spanish. Dissertation Abstracts International, 65(11), 4075A.

Chapelle, C., \& Duff, P. (2003). Some guidelines for conducting quantitative and qualitative research in TESOL. TESOL Quarterly, 37(1), 157-178.

Derwing, T. M. (2003). What do ESL students say about their accents? The Canadian Modern Language Review, 59(4), 547-566.

Ellis, E. M. (2004). The invisible multilingual teacher: The contribution of language background to Australian ESL teachers' professional knowledge and beliefs. International Journal of Multilingualism, I(2), 90-108.

Ellis, E. M. (2002). Teaching from experience: A new perspective on the non-native teacher in adult ESL. Australian Review of Applied Linguistics, 25(1), 71-107.

Fry, R., \& Hakimzadeh, S. (2006). A statistical report of the foreign-born population at mid-decade. Washington, DC: Pew Hispanic Center. Retrieved from http://pewhispanic.org/reports/foreignborn/

Gault, T. R. (2003). Adult Hispanic immigrants' attitudes towards ESL classes. Review of Applied Linguistics, 139, 101-128.

Gault, T. R. (2004). Adult Hispanic immigrants' assumptions regarding good teaching in ESL. Dissertation Abstracts International, 65(5), 1704A.

Gilbertson, S.R. (2000, November). Just enough: A description of instruction at a volunteer-based adult English as a second language program. Dissertation Abstracts International, 61(5), 1709A.

Gordon, D. (2004). "I'm tired. You clean and cook": Shifting gender identities and second language socialization. TESOL Quarterly, 38(3), 437-457.

Gunn, M. (2003). Opportunity for literacy? Preliterate learners in the AMEP. Prospect, 18(2), 37-53.

Hird, B., Thwaite, A., Breen, M., Milton, M., \& Oliver, R. (2000). Teaching English as a second language to children and adults: Variations in practices. Language Teaching Research, 4(1), 3-32.

Hubenthal, W. (2004). Older Russian immigrants' experiences in learning English: Motivation, methods, and barriers. Adult Basic Education, 14(2), 104-126.

Hwang, H-S. (2003). Constructing social identities and language socialization practices in an intermarried family with a transplanted Korean mother. Dissertation Abstracts Intermational, 64(2), 374A.

Hyman, H. K. (2002, January). Foreign-accented adult ESL learners: Perceptions of their accent changes and employability qualifications. Dissertation Abstracts International, 62(7), 2319A.

Izumi, Y., \& Izumi, S. (2004). Investigating the effects of oral output on the learning of relative clauses in English: Issues in the psycholinguistic requirements for effective output tasks. The Canadian Modern Language Review, 60(5), 587-609.

Jeon, M. (2005). Language ideology, ethnicity, and biliteracy development: A Korean-American perspective. Dissertations Abstracts International, 66(6), 2192A-2193A.

Johnson, D. (2001). An annotated bibliography of second language acquisition in adult English language learners. Washington: National Center for ESL Literacy Education.

Kim, J. (2005). A community within the classroom: Dialogue journal writing of adult ESL learners. Adult Basic Education, 15(1), 21-32.

King, K. P. (2000). The adult ESL experience: Facilitating perspective transformation in the classroom. Adult Basic Education, IO(2), 69-90.

Kristjansson, C. R. M. (2004). Whole-person perspectives on learning in community: Meaning and relationships in teaching English as a second language. Dissertation Abstracts International, 65(3), 910A-911A.

Kutner, M., Greenberg, E., \& Baer, J. (2005). A first look at the literacy of American adults in the 21 st century (NCES 2006470). Washington, DC: National Center for Educational Statistics. 
LaBelle, J. (2005). Experiences of ethnic acceptance and prejudice in English language learning: Immigrants' critical reflections. Dissertation Abstracts International, 66(2), 459A.

Lee, E. A. (2000). A study of the effectiveness of interactive multimedia in adult ESL education. Dissertation Abstracts International, 61(4), 1330A.

Maum, R. (2003). A comparison of native and nonnative English speaking teachers' beliefs about teaching English as a second language to adult English language learners. Dissertation Abstracts International, 64(5), 1494A.

McVay, R. H. (2004). Perceived barriers and factors of support for adult Mexican-American ESL students in a community college. Dissertation Abstracts International, 65(5), 1632A.

Menard-Warwick, J. (2005a). Identity and learning in the narratives of Latina/o immigrants: Contextualizing classroom literacy practices in adult ESL. Dissertation Abstracts International, 65(9), 3255A.

Menard-Warwick, J. (2005b). Intergenerational trajectories and sociopolitical context: Latina immigrants in adult ESL. TESOL Quarterly, 39(2), 165-185.

Morgan, B. (2004). Teacher identity as pedagogy: Towards a field-internal conceptualization in bilingual and second language education. International Journal of Bilingual Education and Bilingualism, 7(2/3), 172-188.

Palacios, I. G. (2002, March). An ESL/Literacy Center: A qualitative study of perspectives and practices of immigrant adults and literacy facilitators. Dissertation Abstracts International, 62(9), 3030A.

Panova, I., \& Lyster, R. (2002). Patterns of corrective feedback and uptake in an adult ESL classroom. TESOL Quarterly, 36(4), 573-595.

Reder, S., Harris, K., \& Setzler, K. (2003). The multimedia adult ESL learner corpus. TESOL Quarterly, 37(3), 546-557.

Schomburg, C. R. (2004). Surviving English. Great Plains Research, 14(2), 317-323.

Shono, S. (2005). Good ESL teachers: From the perspectives of teachers and adult learners. Dissertation Abstracts International, 65(8), 2887A-2888A.

Skilton-Sylvester, E. (2002). Should I stay or should I go? Investigating Cambodian women's participation and investment in adult ESL programs. Adult Education Quarterly, 53(1), 8-26.

U.S. Department of Education, Office of Vocational and Adult Education. (2006). Adult Education and Family Literacy Act: Program Year 2003-2004 (Report to Congress on State Performance). Retrieved from http://www.ed.gov/about/reports/annual/ovae/2004aefla.pdf

Warhol, T. (2004). Reassessing assessment practices in an adult ESL program: Liberian women's evaluation of their academic achievement. Working Papers in Educational Linguistics, 20(1), 31-45.

Warriner, D. S. (2003). "Here without English you are dead": Language ideologies and the experiences of women refugees in an adult ESL program. Dissertation Abstracts International, 64(4), 1160A.

Wu, Y., \& Carter, K. (2000). Volunteer voices: A model for the professional development of volunteer teachers. Adult Learning, $1 /(4), 16-20$.

Yang, Y. (2005). Teaching adult ESL learners. Internet TESL Journal, 1/(3). Retrieved September 6, 2006, from http://iteslj.org/Techniques/Yang-AdultLearners.html

Yeh, L-M. (2005). Determination of legitimate speakers of English in ESL discourse. Sociol-cultural aspects of selected issues: Power, subjectivity, and equality. Dissertation Abstracts International, $65(9), 3256 \mathrm{~A}-3257 \mathrm{~A}$. 
Copyright of Adult Education Quarterly is the property of American Association for Adult \& Continuing Education and its content may not be copied or emailed to multiple sites or posted to a listserv without the copyright holder's express written permission. However, users may print, download, or email articles for individual use. 